\title{
Mumps epidemic in orthodox religious low-vaccination communities in the Netherlands and Canada, 2007 to 2009
}

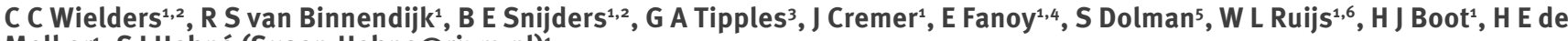
Melker ${ }^{1}$, S J Hahné (Susan.Hahne@rivm.nl) ${ }^{1}$

1. National Institute for Public Health and the Environment (RIVM), Centre for Infectious Disease Control Netherlands, Bilthoven, the Netherlands

2. Pallas health research and consultancy BV, Rotterdam, the Netherlands

3. National Microbiology Laboratory, Public Health Agency of Canada, Winnipeg, Manitoba, Canada

4. Municipal Health Service (GGD) 'Midden Nederland', Zeist, the Netherlands

5. Public Health Protection and Prevention Branch, Public Health Division, Ministry of Health and Long Term Care of Ontario, Toronto, Canada

6. Municipal Health Service (GGD) 'Rivierenland', Tiel, the Netherlands

Citation style for this article:

Wielders CC, van Binnendijk RS, Snijders BE, Tipples GA, Cremer J, Fanoy E, Dolman S, Ruijs WL, Boot HJ, de Melker HE, Hahné SJ. Mumps epidemic in orthodox religious low-vaccination communities in the Netherlands and Canada, 2007 to 2009.

Euro Surveill. 2011;16(41):pii=19989. Available online: http://www.eurosurveillance.org/ViewArticle.aspx?Articleld=19989

Article published on 13 October 2011

We assessed the epidemiological characteristics of a mumps virus epidemic (genotype D) that occurred in the Netherlands between August 2007 and May 2009 and its association with a subsequent mumps outbreak in Canada. In the Netherlands, five data sources were used: notifications (only mandatory since the end of 2008) (56 cases), laboratory confirmation data (177 cases), a sentinel general practitioner (GP) database ( 275 cases), hospitalisation data ( 29 cases) and weekly virological reports (96 cases). The median age of cases in the notification, laboratory and GP databases ranged from 13 to 15 years. The proportion of cases that were unvaccinated ranged from $65 \%$ to $85 \%$ in the notification, laboratory and GP databases. Having orthodox Protestant beliefs was the main reason for not being vaccinated. In Canada, a mumps virus strain indistinguishable from the Dutch epidemic strain was detected between February and October 2008 in an orthodox Protestant community with historical and family links to the affected community in the Netherlands, suggesting that spread to Canada had occurred. Prevention and control of vaccine-preventable diseases among population subgroups with low vaccination coverage remains a priority.

\section{Introduction}

Mumps (parotitis epidemica) is a vaccine-preventable viral infection characterised by inflammation of the salivary glands. Complications include aseptic meningitis, deafness, encephalitis, orchitis and oophoritis [1]. In the Netherlands, the disease had been notifiable between 1976 and 1998, and became notifiable again in 2008 [2], following a review of the criteria for notification of infections.
In 1987, the combination vaccine against measles, mumps and rubella (MMR) was introduced in the Dutch National Immunisation Programme for all children aged 14 months and nine years. Since 1995, the estimated nationwide MMR coverage (measured by registration of the vaccination status for each Dutch child individually) for one dose has not been below 95\% (in twoyear-olds); for the second dose, the coverage is slightly lower, around 93\% (in nine-year-olds) [3]. The mumps vaccine used contains the Jeryl Lynn mumps JL2 and JL5 vaccine strains [2]. The high coverage for the entire country, however, is not reached in areas where a part of the population refuses vaccination based on their orthodox Protestant beliefs [3,4]. In one of the municipalities where these groups reside, coverage for the first dose of the MMR vaccine in 2009 was as low as $62 \%$ [5]. About $1.5 \%$ of the Dutch population belongs to this minority of an estimated 250,000 persons [6].

Between August 2007 and May 2009, a mumps epidemic in the country was detected through laboratory surveillance $[2,7]$, but assessment of the extent and characteristics of the epidemic was hampered by the absence of mandatory notification between January 1999 and December 2008 [8]. A subsequent mumps outbreak (in February to October 2008) was observed in Canada, with the first case identified in July 2008 , nearly a year after the epidemic started in the Netherlands.

Mumps is a notifiable disease in Canada (notifiable during 1924 to 1959 and from 1986 onwards) [9]. The estimated MMR vaccine coverage for one dose in two-year-old children has not been below 93\% since 2002 [10]. However, similar to the Netherlands, this overall figure conceals areas of lower coverage in 
geographically clustered communities in Canada (in south-western Ontario) who refuse vaccination for orthodox Protestant reasons (population estimate unavailable). Historically, members of this Canadian community have had close family relationships with the orthodox Protestants in the Netherlands. Several outbreaks of vaccine-preventable diseases have spread from the Netherlands to these Canadian communities in the past, including poliomyelitis, measles and rubella [11-14]. Spread of an outbreak of a vaccine-preventable disease from Canada to the Netherlands, however, has never been documented.

The aim of our study was to assess the epidemiological characteristics of the mumps epidemic in 2007 to 2009 in the Netherlands and to study its association with the subsequent mumps outbreak in Canada.

\section{Data sources in the Netherlands}

To describe the epidemiological characteristics associated with the mumps outbreak in the Netherlands, five data sources were used. As there was no common identifier, unfortunately, these databases could not be linked.

\section{Notification database (Osiris)}

From 1 December 2008, mumps became again a notifiable disease in the Netherlands. Data of patients registered in the nationwide mandatory notification system, Osiris, with a date of symptom onset from 1 December 2008 up to 31 May 2009 were available (date of sampling was used when date of onset was unknown).

The case definition for notification was a person with at least one of the following three symptoms: (i) acute onset and painful swelling of the parotid or other salivary gland, (ii) orchitis and (iii) meningitis (clinical criteria for orchitis and meningitis were not specified); in addition, at least one of the two following criteria was met: laboratory-confirmed infection with mumps virus or contact (less than four weeks ago) with a person who had laboratory-confirmed mumps. Laboratory confirmation of infection with mumps virus included detection of mumps virus-specific IgM antibody in serum, detection of mumps virus RNA in oral fluid, oropharyngeal swab or urine specimens by reverse transcription (RT)-PCR or by virus culture. People who had been vaccinated less than four weeks before symptom onset were not notified, unless wild-type mumps virus RNA was detected.

\section{Laboratory database}

The Centre for Infectious Disease Control Netherlands at the National Institute for Public Health and the Environment (RIVM) serves as a reference laboratory for mumps. Early in the epidemic, municipal health services were asked to encourage physicians to send samples from mumps cases who had been vaccinated. This meant that unvaccinated cases were under-represented in the laboratory data.
A case was defined on basis of laboratory confirmation, which was either detection of mumps virus RNA in throat swabs, oral fluid or urine specimens by RT-PCR or detection of mumps virus-specific IgM in serum or dried blood spot specimens or, occasionally, on the basis of a fourfold rise in mumps virus-specific IgG titre [15]. The laboratory database contained information on sex, age, mumps virus genotype, date of symptom onset, vaccination status, reason for non-vaccination and PCR, IgM, IgG test results.

Data from all laboratory-confirmed cases with a date of symptom onset between 22 August 2007 (the date symptoms of the first case began) and 31 May 2009 were available.

\section{General practitioners (GP) database}

Enhanced sentinel surveillance was carried out in 11 GP practices situated in low vaccine coverage areas between 1 September 2007 and 31 December 2008. Cases were defined as patients with a clinical or laboratory-confirmed diagnosis of mumps (the clinical criteria for meningitis, orchitis or encephalitis were not specified and the requirements for laboratory confirmation were not specified in the database). The monthly incidence of the disease reported through this system was determined for three periods (September 2007 to March 2008, April to June 2008 and July to December 2008), as not all GPs participated during the entire study period.

\section{National Medical Registry}

We analysed the number of hospitalisations in 2006 to 2009 due to mumps or mumps-related complications from the National Medical Registry, to which all academic and general (and almost all specialised) hospitals supplied data. We included data from 2006 to show the number of diagnoses before the epidemic. Admissions from hospitals with incomplete reporting

\section{TABLE}

International Classification of Diseases codes used for analysis of hospital diagnoses related to mumps, the Netherlands, 2006-2009

\begin{tabular}{|l|c|}
\hline Diagnosis & ICD-9-CM code \\
\hline Mumps & 072 \\
\hline Mumps orchitis & 072.0 \\
\hline Mumps meningitis & 072.1 \\
\hline Mumps encephalitis & 072.2 \\
\hline Mumps pancreatitis & 072.3 \\
\hline Mumps with other specified complications & 072.7 \\
\hline Mumps hepatitis & 072.71 \\
\hline Mumps polyneuropathy & 072.72 \\
\hline Mumps with other complication & 072.79 \\
\hline Mumps with unspecified complication & 072.8 \\
\hline Mumps without complications & 072.9 \\
\hline
\end{tabular}

ICD-9-CM: International Classification of Diseases, ninth revision, clinical modification [16]. 
were excluded from the analysis, leaving data from approximately $75 \%$ of all hospitals in the Netherlands.

The diagnoses in the hospitals were defined according to the International Classification of Diseases, ninth revision, clinical modification (ICD-9-CM) [16]. The Table shows all the ICD-9-CM diagnoses that were considered. The National Medical Registry database also contains information on age, sex, date of hospital admission and discharge, main diagnosis and minor diagnoses.

\section{Weekly virological reports}

Since 1989, 21 medical microbiological laboratories in the country have reported their weekly number of positive virological test results, including detection of mumps virus, to the laboratory surveillance system (the reference laboratory is not included). Reporting is voluntary, but it is constant and complete. Only the number of positive samples is reported: no information about the number of samples tested or clinical information about the cases is available. This data source is particularly useful to detect trends over time. We used the reports from 2006 to 2009 (data from 2006 were included to show the number of diagnoses in a year without an epidemic).

\section{FIGURE 1}

Laboratory-confirmed mumps cases diagnosed by the national reference laboratory at RIVM, by municipality and vaccination status, the Netherlands, August 2007May $2009(\mathrm{n}=165)^{\mathrm{a}}$

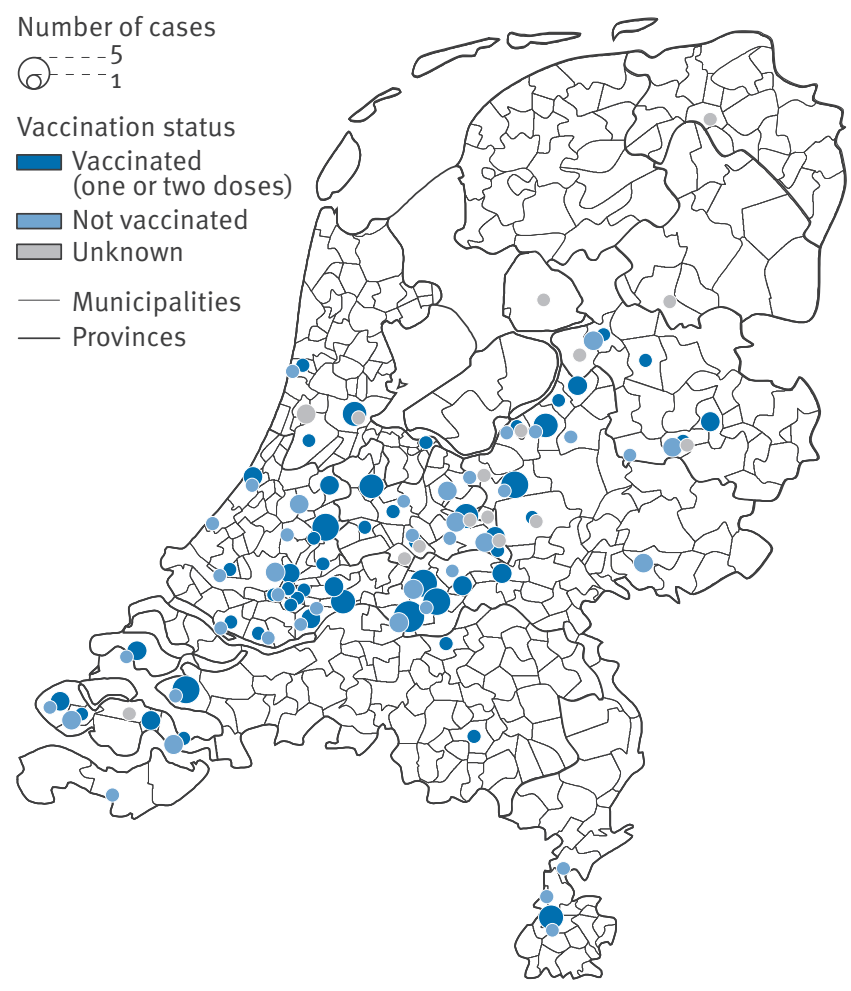

RIVM: National Institute for Public Health and the Environment. a 12 cases were not included because of missing information. Source: RIVM.

\section{Description of the epidemic} in the Netherlands

Notification database (Osiris)

A total of 56 cases with a date of symptom onset between 1 December 2008 and 31 May 2009 were registered in the national mandatory notification system, Osiris. The cases had a median age of 15 years (range: 1-56); 29 were male. For 10 cases, complications due to mumps were reported: seven of these had orchitis. The seven cases with orchitis were all unvaccinated; the three remaining cases with complications had received one dose of MMR vaccine (two cases had been vaccinated six months before diagnosis and one case had been vaccinated three years before diagnosis). Three of the 56 cases were hospitalised due to their complications (two because of orchitis, one had an abscess): the case with the abscess had received one dose of MMR vaccine and the other two cases were unvaccinated.

Vaccination status was known for 55 of the 56 cases: 40 had not been vaccinated. Of the 15 that had been vaccinated, nine had received one dose, five had received two doses and for one case, the number of doses was unknown. The median age of the unvaccinated cases was 17 years (range: 1-56); for cases vaccinated at least once, it was 9 years (range: $1-26)(p=0.02)$. For 32 of the 40 unvaccinated cases, a reason for

\section{FIGURE 2}

Measles-mumps-rubella vaccination coverage at the age of 10 years, by municipality, the Netherlands, $2006^{\mathrm{a}}$

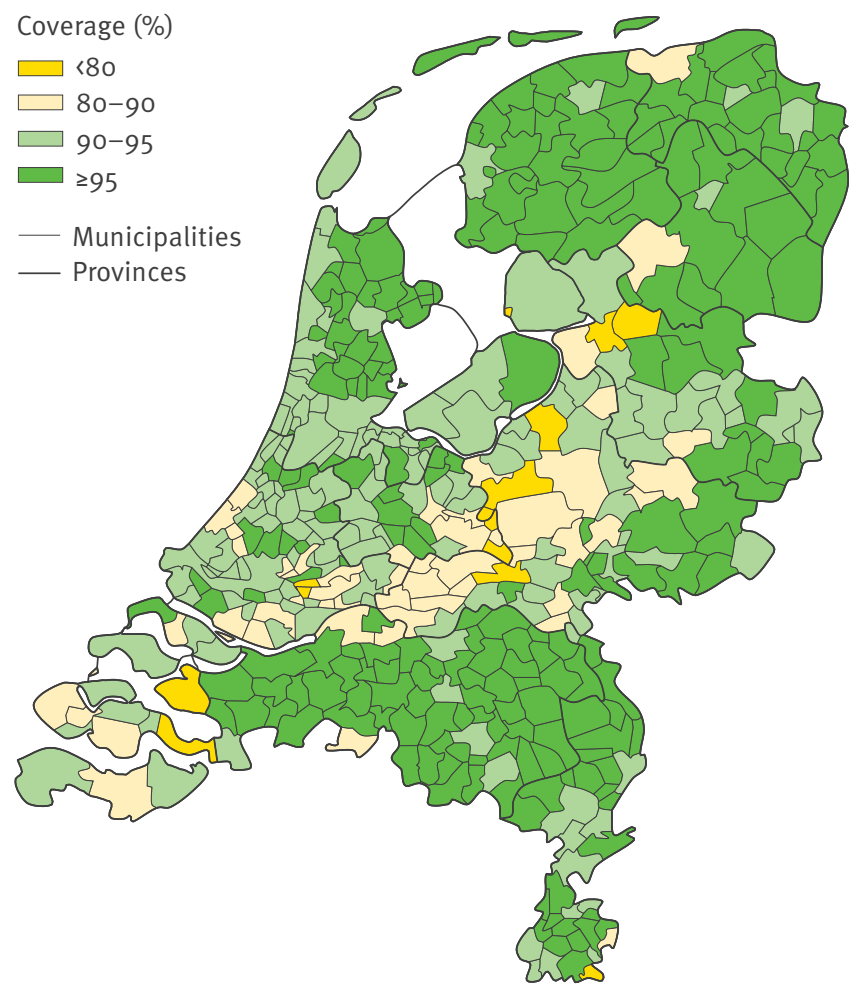

1995 birth cohort, completed vaccination at the age of 10 years. Source: De Nationale Atlas Volksgezondheid [The Dutch National Atlas of Public Health]. 
non-vaccination was reported. The most frequent reason was having orthodox Protestant beliefs $(n=27)$ and five cases had a critical attitude towards vaccination.

\section{Laboratory database}

The national reference laboratory received samples from 409 suspected cases with a date of onset symptoms between 22 August 2007 and 31 May 2009. In total, $43 \%(n=177)$ were confirmed as mumps cases. Most of these patients were not notified since mandatory notification started only in December 2008. The median age of the confirmed cases was 13 years (range: 1 month-56 years). Vaccination status was known for $156(88 \%)$ of the confirmed cases. Some $(35 \% ; n=55)$ of these cases were vaccinated: 26 had been vaccinated once, 29 twice and 101 cases were unvaccinated. The median age of unvaccinated cases was 14 years (range: 1 month-56 years); for vaccinated cases, it was nine years (range: $1-29$ years), $p=0.00$.

For 72 of the 101 unvaccinated cases, a reason for nonvaccination was reported. The reasons were religious beliefs $(n=52)$, the age of the case $(n=13$, of which four were too young to be eligible for vaccination) and nine cases were born before vaccination against mumps had been introduced in the Netherlands), four had a critical attitude towards vaccination, and three had an anthroposophical lifestyle. Figure 1 shows the geographical distribution of laboratory-confirmed cases in the Netherlands from August 2007 to May 2009 by vaccination status and Figure 2 illustrates the MMR vaccination coverage in 2006 (having received two doses at the age of 10 years) of the 1995 birth cohort.

Figure 3 shows an epidemic curve of the mumps cases recorded through the notification and laboratory databases.

Virus genotyping results were available for 158 (89\%) of the 177 laboratory-confirmed cases. The most frequent genotype was $D(n=145 ; 92 \%)$; the remaining samples were genotype $G(n=13 ; 8 \%)$. The 13 patients with genotype $\mathrm{G}$ had a date of symptom onset between February 2008 and April 2009. Of these, vaccination status was known for 10 patients: eight had been vaccinated (three had been vaccinated once, five had been vaccinated twice) and two were unvaccinated. Cases with genotype $\mathrm{G}$ were predominantly living in areas with higher vaccination coverage. There was one orthodox Protestant among the unvaccinated cases

\section{FIGURE 3}

Mumps cases registered through mandatory notification $(n=56)^{a}$ and laboratory-confirmed cases $(n=177)$, by week of symptom onset ${ }^{\mathrm{b}}$, the Netherlands, 2007-2009c

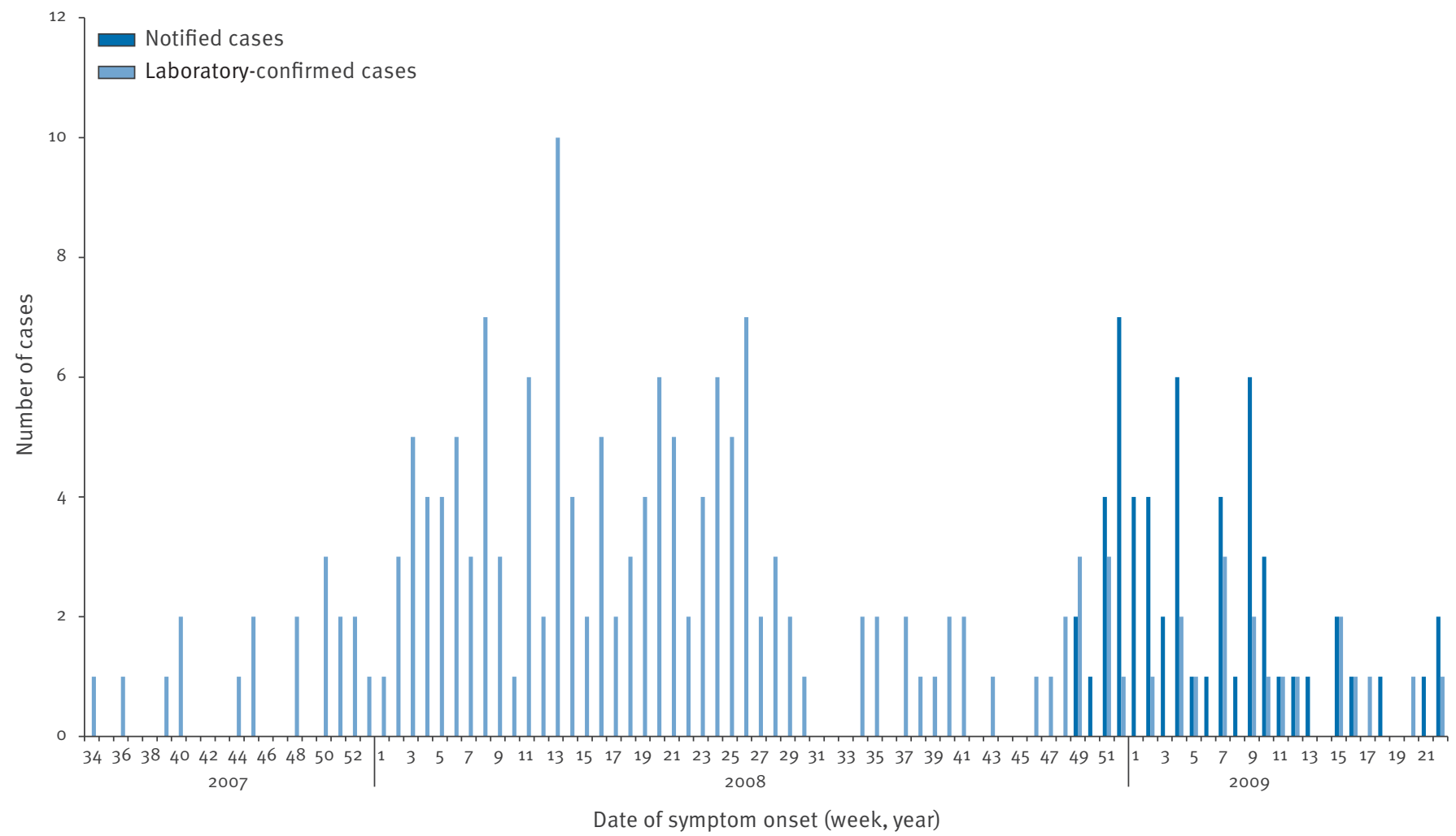

a Mumps was not notifiable between January 1999 and December 2008.

${ }^{b}$ When the date of onset of symptoms was unknown, date of sampling was used.

' For the notified cases, 1 December 2008-31 May 2009 (week 49 2008-week 22 2009). For the laboratory-confirmed cases, 22 August 2007-31 May 2009 (week 34 2007-week 22 2009). 
with genotype $\mathrm{G}$ and one case was too young to be vaccinated.

\section{General practitioners database}

The enhanced sentinel surveillance in $11 \mathrm{GP}$ practices situated in low vaccine coverage areas resulted in detection of 275 mumps cases from 1 September 2007 to 31 December 2008. Their median age was 14 years (range: 1-67). The age distribution of cases from the notification, laboratory and GP databases is shown in Figure 4 .

Of the $\mathbf{2 7 5}$ cases detected through the enhanced sentinel surveillance, $59 \%(n=163)$ were male. After excluding cases for whom only age and sex were recorded $(n=69$, reported by one GP), a total of 206 cases were included in our analysis. GPs reported whether there had been laboratory confirmation of the infection and decided whether to send samples for testing. Mumps diagnosis was confirmed by laboratory testing for 16 of the 206 cases $(8 \%)$.

From September 2007 to December 2008, the 11 sentinel GP practices covered 38,281 people: in September 2007 to March 2008, the population covered was 34,981, in April to June 2008, it was 29,281 and in July to December 2008, it was 6,150. The estimated monthly incidence of mumps in these GP practices was 34.6 (95\% Cl: 27.9-42.5) per 100,000 population per month in September 2007 to March 2008 (n=92), 102.9 (95\% Cl: 82.1-127.1) per 100,000 population per month in April to June $2008(n=85)$ and 180.1 (95\% Cl: 139.7228.4) per 100,000 population per month between July and December $2008(n=67)$. As not all GP practices

\section{FIGURE 4}

Age distribution of mumps cases registered in the notification database $(n=56)$, laboratory database $(n=177)$ and general practitioners database $(n=275)$,

the Netherlands, 2007-2009a

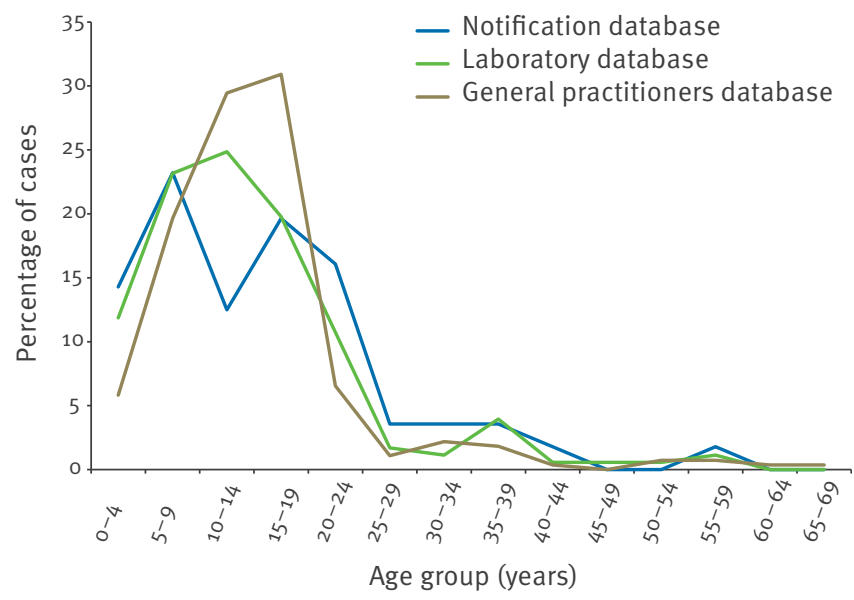

Notification database: 1 December 2008-31 May 2009; laboratory database: 22 August 2007-31 May 2009; general practitioners database: 1 September 2007-31 December 2008. reported throughout the study period, an epidemic curve would not be meaningful.

Of the 206 cases analysed, 85\% $(n=176)$ were unvaccinated. Their median age was 14 years (range: $1-67$ ). The median age of the vaccinated cases $(n=30)$ was 13 years (range: $4-31$ ), $p=0.44)$. Three had been vaccinated once, 10 had been vaccinated twice and five had been vaccinated either once or twice, while for 12 , the number of vaccinations was unknown. Orthodox Protestant beliefs were the main reason for not being vaccinated (held by 163 (93\%) of the 176 unvaccinated cases).

The median number of household members of the 206 cases analysed was six (range: $1-11)$. The median attack rate in their households was 50\% (range: 13-100). Complications of mumps were reported in 33 (16\%) cases. Of the 123 cases who were male, 25 (20\%) had orchitis. Seven (3.4\%) of all 206 cases had meningitis (including one case for whom meningitis was not confirmed) and one (0.5\%) had encephalitis.

\section{National Medical Registry}

The number of hospitalisations due to mumps or mumps-related complications in 2006 to 2009 is presented in Figure 5. The outbreak peaked in May 2008, as documented from mumps related hospitalisations and weekly virological reports. The duration of the epidemic can be clearly seen from the hospitalisation data, with its peak in May 2008. During the epidemic, 29 patients were hospitalised due to mumps or a mumps-related complication: they accounted for $78 \%$ of all hospitalisations due to mumps during 2006 to 2009 in the Netherlands $(n=37)$. A peak of seven admissions was observed in May 2008. There was another hospitalisation in June 2009, but as no new mumps cases with genotype $D$ virus had been diagnosed in the laboratory database after 31 May 2009, we did not consider this case as part of the epidemic.

\section{Weekly virological reports}

The number of tests that were positive for mumps virus from the weekly virological reports from 2006 to 2009 is shown in Figure 5. The peak number of positive tests was observed in May $2008(n=13)$, which coincided with the peak in hospitalisations due to mumps or mumps-related complications. Of all positive tests in 2006 to $2009(n=120), 80 \%(n=96)$ were observed during the epidemic (August 2007 to May 2009).

\section{Spread to Canada}

The Ontario Ministry of Health and Long-Term Care was notified by the regional health unit on 1 August 2008 about an outbreak of mumps. Outbreak-associated cases were identified retrospectively to 24 February 2008. The date of symptom onset of the last case of the outbreak was 26 October 2008; the majority of cases $(n=288 / 324 ; 88 \%)$ had symptom onset between June and August 2008 and were mainly school-age children, with $77 \%(250 / 324)$ between the ages of 5 and 19 
years. The cases were all from Ontario [17], mainly in the south-west of the province in a community with low immunisation coverage.

A confirmed outbreak case was defined as a person having any of the following, in the absence of mumps vaccination in the previous 28 days: (i) a positive serological test for mumps-specific IgM, with an acute onset of unilateral or bilateral parotitis lasting longer than two days without other apparent cause, (ii) demonstrated seroconversion or a fourfold increase in the titre of mumps virus-specific IgG between the acute and convalescent sera titres, or (iii) the detection of mumps virus RNA from urine or buccal swabs [18]. Symptomatic people who had an epidemiological link to a laboratory-confirmed case were also considered as confirmed outbreak cases.

All case and laboratory data were entered into Ontario's integrated Public Health Information System. There were 324 outbreak-associated cases reported, of which $289(89.1 \%)$ were confirmed cases. Samples from nine of the confirmed cases were received at the National Microbiology Laboratory of the Public Health Agency of Canada between 30 July and 12 September 2008. Mumps virus genotyping was done as per the internationally accepted standard [19]. The sequences of the mumps virus strains from the samples were compared with the sequence of the Dutch outbreak strain and were submitted to GenBank. Phylogenetic analysis of the different mumps viruses was based on nucleotide sequencing of the coding region of the small hydrophobic (SH) gene of mumps virus RNA (317 base pairs) using the neighbour-joining method for phylogenetic comparison and using a set of reference genotypes obtained from GenBank [20].

All nine viral sequences were $100 \%$ identical and were indistinguishable from the Dutch genotype $D$ epidemic strain, based on the same 317 bp sequence of the SH gene. Figure 6 shows the phylogenetic tree of Dutch $(n=5)$ and Canadian $(n=1)$ isolates and reference genotypes. A tenth sample was found to contain genotype $\mathrm{G}$ (importation from British Columbia), a genotype that has circulated in mumps outbreaks in North America since 2006 [21-24]. This sample had been taken from a member of the religious community with symptom onset on 8 September 2008 , who had been originally thought to be part of the outbreak. As only a few samples were sent for genotyping, other people with mumps may also have been infected with a genotype $G$ strain. This illustrates how people with the disease may appear to be part of the same cluster, as they appear linked in time and place, while they may in fact have been exposed to different sources of the virus and are thus not part of the cluster.

\section{FIGURE 5}

Monthly hospitalisations due to mumps or mumps-related complications recorded in the National Medical Registry and the number of tests positive for mumps virus in the weekly virological reports, the Netherlands, 2006-2009

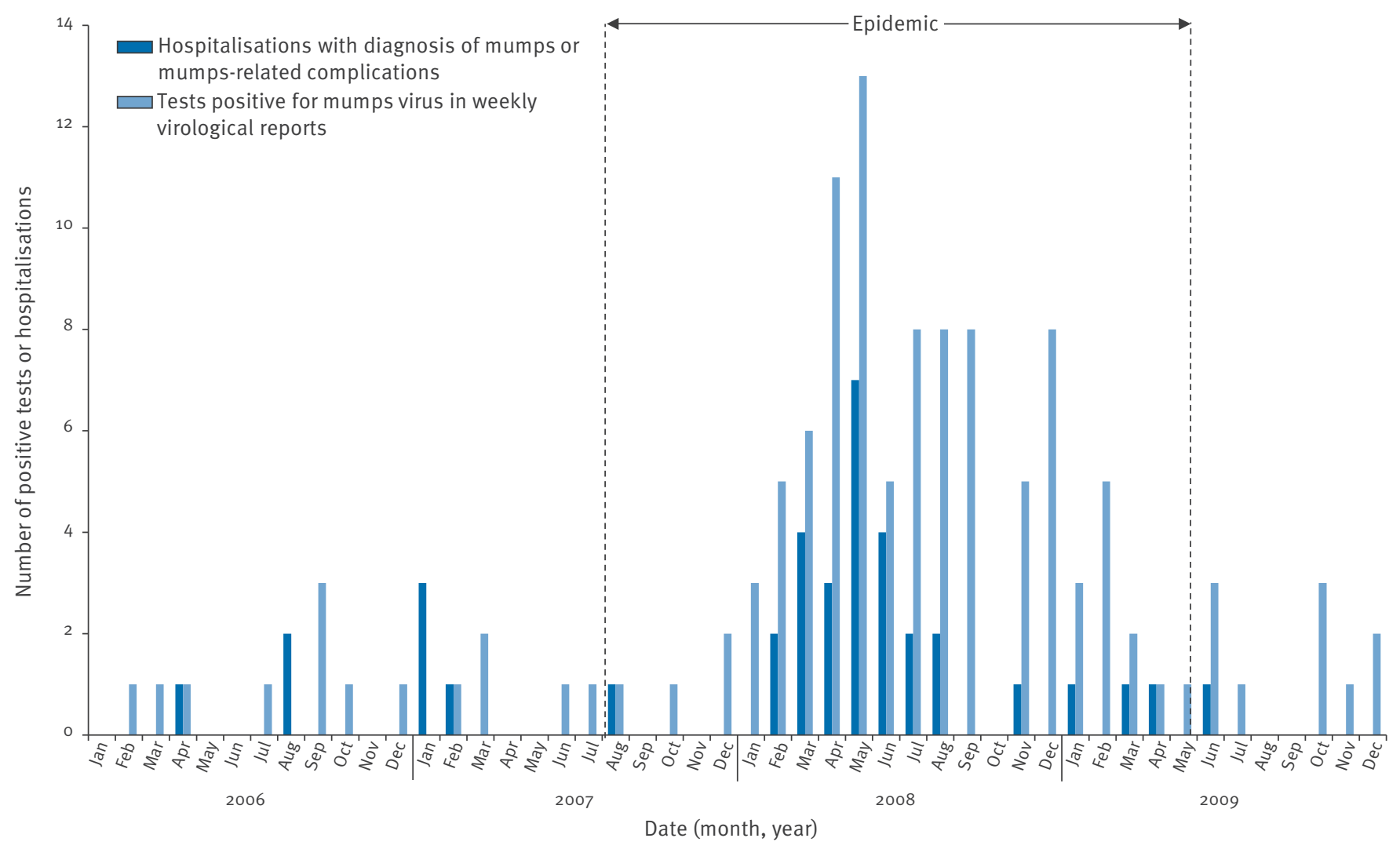




\section{Discussion and conclusion}

In this mumps epidemic in the Netherlands, most cases were living in low vaccination coverage areas and were unvaccinated, orthodox Protestant children. The orthodox Protestant population has been affected by several outbreaks of vaccine-preventable diseases, including poliomyelitis in 1978 and in 1992 to 1993 [25,26], measles in 1999 to 2000 [14] and rubella in 2004 to 2005 [12].

We believe that the vaccination status of cases can most reliably be estimated from the mandatory notification system. On the basis of the notification data, an estimated $27 \%$ of cases $(n=15)$ had been vaccinated. Mumps among vaccinated individuals has been described in the literature [27-30]: possible causes are primary vaccine failure, secondary vaccine failure or waning immunity, and a mismatch between vaccine- induced immunity and the wild-type mumps virus strain [27,29-34].

The proportion of cases with a complication ranged from $16 \%(33 / 206)$ in the GP database to $18 \%(10 / 56)$ in the notification database. As patients with complications are likely to be overrepresented among those visiting a GP and those notified, both proportions are likely to be overestimates. Three of the 56 notified cases required hospital admission. The hospitalisation database, which covers approximately $75 \%$ of the Netherlands, registered 29 mumps-related hospitalisations during the epidemic. Compared with previous outbreaks of rubella and measles in the Netherlands, with $2 \%$ and $1 \%$ of cases admitted to hospital, respectively $[12,14]$, the percentage of hospitalisations during the mumps epidemic was higher.

\section{FIGURE 6}

Phylogenetic tree of reference mumps virus genotypes and genotype D and G branches harbouring the reference strains and the Dutch $(\mathrm{n}=5)$ and Canadian $(\mathrm{n}=1)$ isolates, 2007-2009

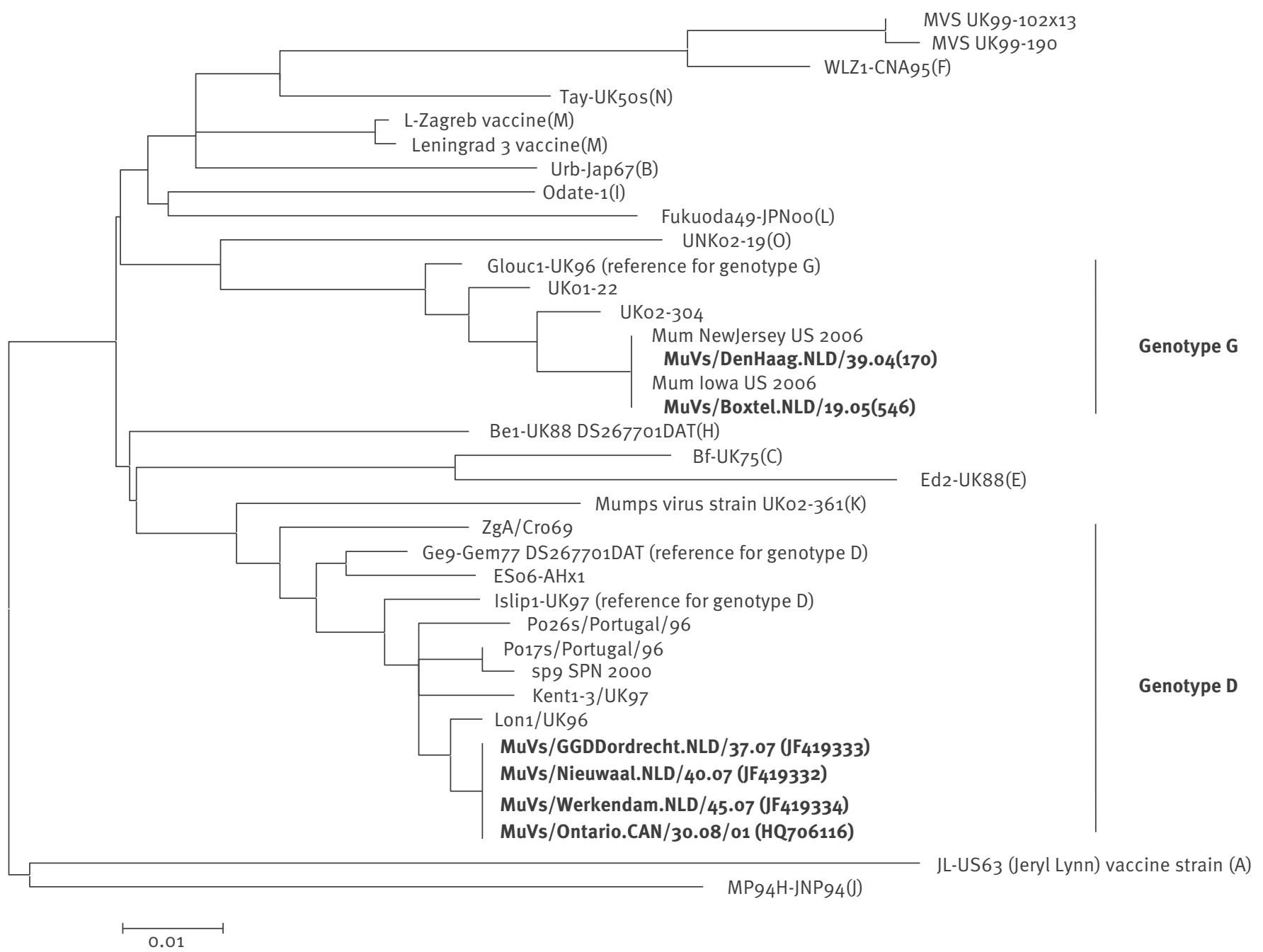

Evolutionary distances are reflected as branch lengths. The distance indicator (length) reflects the fraction of nucleotide difference. The Dutch (NLD) and Canadian (CAN) isolates are shown in bold. 
The spread of the mumps outbreak to Canada was not unexpected, as previous outbreaks of vaccine-preventable diseases had also spread to Canada [11-14]. The first case with mumps virus genotype $D$ that was indistinguishable from the Dutch epidemic strain was identified in July 2008 , nearly a year after the outbreak started in the Netherlands. This indicates that the virus had spread from the Netherlands to Canada and not vice versa. We suppose that close family relationships and subsequent visits of relatives caused the spread to Canada. We do not have any information about the occurrence of the Dutch epidemic strain in other countries.

There were several limitations in our study. Firstly, there was no single data source available that had complete information on all cases during the mumps epidemic in the Netherlands. Mumps was not a notifiable disease in the country up to December 2008. The laboratory database included cases diagnosed during the whole epidemic; however, due to increased awareness of the possible emergence of outbreaks among vaccinated persons, physicians were particularly encouraged to send samples of vaccinated mumps patients, so these data are not representative for the epidemic. Further, the laboratory database mostly includes data obtained from the national reference laboratory and very few from the peripheral laboratories in the Netherlands. It was, however, the only data source for genotype results. The GP database included data from GPs in low vaccination coverage areas, which results in estimates that are not representative. However, with the five data sources used in this study, we were able to give the best available description of the epidemic. Secondly, we were not able to link data sources as there was no unique identifier. Therefore it is possible that some cases were present in one or more data sources. Since we did not merge any of the data sets, this should not have affected our conclusions. Finally, the fact that different time periods were covered in the data sources is also a limitation.

At present, a new mumps outbreak is ongoing in the Netherlands mainly among students [35]. This outbreak started in December 2009, caused by mumps virus genotype $G$. Genotype $G$ strains were also found in 2008, mainly among vaccinated individuals (data not shown). In contrast to the 2007 to 2009 epidemic, the majority of the students with mumps had been vaccinated: $80 \%$ had received at least one dose and $75 \%$ had been vaccinated at least twice [35]. The spread of this outbreak is being monitored closely and a study into risk factors has been initiated.

In conclusion, our study of a mumps epidemic mainly among unvaccinated orthodox Protestant individuals demonstrates that a focus on interventions to prevent and control vaccine-preventable diseases in population subgroups with low or intermediate vaccination coverage remains necessary, in the Netherlands and elsewhere. i.
Acknowledgments

We would like to thank patients, clinicians and staff of laboratories and of municipal health services for their contribution to generating the information reported in this manuscript. We also would like to thank Henriette Giesbers, (RIVM), Daphne Gijselaar (RIVM), Joanne Hiebert and Jennifer Beirnes from the National Microbiology Laboratory (Public Health Agency of Canada), as well as Ellen Chan from the Surveillance Section, Ontario Ministry of Health and LongTerm Care, for their contributions.

\section{References}

1. Hviid A, Rubin S, Muhlemann K. Mumps. Lancet. 2008;371(9616):932-44.

2. Kemmeren JM, de Melker HE. The National Immunisation Programme in the Netherlands. Developments in 2009. Bilthoven: National Institute for Public Health and the Environment (RIVM); 2010. Report 210021012/2010. Available from: http://www.rivm.nl/bibliotheek/rapporten/210021012. pdf

3. van Lier EA, Oomen PJ, Oostenbrug MW, Zwakhals SL, Drijfhout $\mathrm{IH}$, de Hoogh PA, et al. [High vaccination coverage of the National Immunization Programme in the Netherlands]. Ned Tijdschr Geneeskd. 2009;153(20):950-7. Dutch .

4. Ruijs WL, Hautvast JL, van der Velden K, de Vos S, Knippenberg $\mathrm{H}$, Hulscher ME. Religious subgroups influencing vaccination coverage in the Dutch Bible belt: an ecological study. BMC Public Health. 2011;11:102.

5. Zwakhals SLN, van Lier EA. BMR per gemeente 2010 (zuigelingen) [MMR-1 coverage by municipality 2010 (infants)]. Dutch Public Health Status and Forecast studies, National Compass of Public Health. Bilthoven: National Institute for Public Health and the Environment (RIVM); 2010. [Accessed 19 Jan 2011]. Dutch. Available from: http:// www.zorgatlas.nl/preventie/vaccinaties-en-screening/ bmr-per-gemeente-2010-zuigelingen/\#breadcrumb

6. Ruijs WL, Hautvast JL, van Ansem WJ, Akkermans RP, van't Spijker K, Hulscher ME, et al. Measuring vaccination coverage in a hard to reach minority. Eur J Public Health. 2011 Jun 29. [Epub ahead of print].

7. Karagiannis I, van Lier A, van Binnendijk R, Ruijs H, Ruijs H, Fanoy E, et al. Mumps in a community with low vaccination coverage in the Netherlands. Euro Surveill. 2008;13(24): pii=18901. Available from: http://www. eurosurveillance.org/ViewArticle.aspx?Articleld=18901

8. van den Hof S, Conyn-van Spaendonck MAE, de Melker HE, Geubbels ELPE, Suijkerbuijk AWM, Talsma E, et al. The effects of vaccination, the incidence of the target diseases. Bilthoven: National Institute for Public Health and the Environment (RIVM); 1998. RIVM report 213676008 . Available from: http:// www.rivm.nl/bibliotheek/rapporten/213676008.pdf

9. Public Health Agency of Canada. National notifiable diseases. Public Health Agency of Canada; 2005. [Accessed 20 Jul 2011]. Available from: http://dsol-smed.phac-aspc.gc.ca/dsol-smed/ ndis/list-eng.php

10. Public Health Agency of Canada. Canadian national report on immunization, 2006. 2006. Can Commun Dis Rep.2006;32S3:1-44. Available from: http://www.phac-aspc. gc.ca/publicat/ccdr-rmtc/06pdf/32s3_e.pdf

11. Furesz J, Armstrong RE, Contreras G. Viral and epidemiological links between poliomyelitis outbreaks in unprotected communities in Canada and the Netherlands. Lancet. 1978;2(8102):1248.

12. Hahné S, Macey J, van Binnendijk R, Kohl R, Dolman S, van der Veen Y, et al. Rubella outbreak in the Netherlands, 2004-2005: high burden of congenital infection and spread to Canada. Pediatr Infect Dis J. 2009;28(9):795-800.

13. Drebot MA, Mulders MN, Campbell JJ, Kew OM, Fonseca K, Strong D, et al. Molecular detection of an importation of type 3 wild poliovirus into Canada from The Netherlands in 1993. Appl Environ Microbiol. 1997;63(2):519-23.

14. van den Hof S, Conyn-van Spaendonck MA, van Steenbergen JE. Measles epidemic in the Netherlands, 1999-2000. J Infect Dis. 2002;186(10):1483-6.

15. Baas MC, van Donselaar KA, Florquin S, van Binnendijk RS, ten Berge IJ, Bemelman FJ. Mumps: not an innocent bystander in solid organ transplantation. Am J Transplant. 2009;9(9):2186-9.

16. Centers for Disease Control and Prevention (CDC). International Classification of Diseases, ninth revision, clinical modification 
(ICD-9-CM). Atlanta: CDC; 2010. [Accessed 19 Jul 2011]. Available from: http://www.cdc.gov/nchs/icd/icd $9 \mathrm{~cm} . \mathrm{htm}$

17. Chan EOM, Carr DJ, Dolman S. Epidemiology of the 2008 mumps outbreak in Oxford County, Ontario. [Presentation at the Association of Public Health Epidemiologists in Ontario, (CSEB/APHEO Joint Conference), Ottawa, Ontario, Canada, 24-28 May 2009, and at the Ontario Public Health Conference, Toronto, Ontario, Canada, 1-4 November 2009]. Available from: http://www.ophaconference.ca/2009/pdfs/OPHAo9-Co6BP1EChan.pdf

18. Tipples GA, Hiebert J. Detection of measles, mumps, and rubella viruses. In: Stephenson JR, Warnes A, editors. Diagnostic virology protocols: Springer Science and Business Media; 2011. p. 183-93.

19. Jin L, Rima B, Brown D, Orvell C, Tecle T, Afzal M, et al. Proposal for genetic characterisation of wild-type mumps strains: preliminary standardisation of the nomenclature. Arch Virol. 2005;150(9):1903-9.

20. Jin L, Beard S, Brown DW. Genetic heterogeneity of mumps virus in the United Kingdom: identification of two new genotypes. J Infect Dis. 1999;180(3):829-33.

21. Centers for Disease Control and Prevention (CDC). Update: multistate outbreak of mumps--United States, January 1-May 2, 2006. MMWR Morb Mortal Wkly Rep. 2006;55(20):559-63.

22. Centers for Disease Control and Prevention (CDC). Mumps outbreak - New York, New Jersey, Quebec, 2009. MMWR Morb Mortal Wkly Rep. 2009;58(45):1270-4.

23. Peltola H, Kulkarni PS, Kapre SV, Paunio M, Jadhav SS, Dhere RM. Mumps outbreaks in Canada and the United States: time for new thinking on mumps vaccines. Clin Infect Dis. 2007;45(4):459-66.

24. Public Health Agency of Canada. Update on mumps outbreak in the Maritimes. National summary, September 14, 2007. Available from: http://www.phac-aspc.gc.ca/mumps-oreillons/ pdf/mumps-oreillons070914_e.pdf

25. Bijkerk H, Draaisma FJ, van der Gugten AC, van Os M. [The poliomyelitis epidemic in 1978]. Ned Tijdschr Geneeskd. 1979;123(39):1700-14. Dutch.

26. Oostvogel PM, van Wijngaarden JK, van der Avoort HG, Mulders MN, Conyn-van Spaendonck MA, Rümke HC, et al. Poliomyelitis outbreak in an unvaccinated community in The Netherlands, 1992-93. Lancet. 1994;344(8923):665-70.

27. Brockhoff HJ, Mollema L, Sonder GJ, Postema CA, van Binnendijk RS, Kohl RH, et al. Mumps outbreak in a highly vaccinated student population, The Netherlands, 2004. Vaccine. 2010;28(17):2932-6.

28. Marin M, Quinlisk P, Shimabukuro T, Sawhney C, Brown $C$, Lebaron CW. Mumps vaccination coverage and vaccine effectiveness in a large outbreak among college students-lowa, 2006. Vaccine. 2008;26(29-30):3601-7.

29. Park DW, Nam MH, Kim JY, Kim HJ, Sohn JW, Cho Y, et al. Mumps outbreak in a highly vaccinated school population: assessment of secondary vaccine failure using IgG avidity measurements. Vaccine. 2007;25(24):4665-70.

30. Vandermeulen C, Roelants M, Vermoere M, Roseeuw K, Goubau $P$, Hoppenbrouwers K. Outbreak of mumps in a vaccinated child population: a question of vaccine failure? Vaccine. 2004;22(21-22):2713-6.

31. Briss PA, Fehrs LJ, Parker RA, Wright PF, Sannella EC, Hutcheson RH, et al. Sustained transmission of mumps in a highly vaccinated population: assessment of primary vaccine failure and waning vaccine-induced immunity. J Infect Dis. 1994;169(1):77-82.

32. Cohen C, White JM, Savage EJ, Glynn JR, Choi Y, Andrews N, et al. Vaccine effectiveness estimates, 2004-2005 mumps outbreak, England. Emerg Infect Dis. 2007;13(1):12-7.

33. Dayan GH, Quinlisk MP, Parker AA, Barskey AE, Harris ML, Schwartz JM, et al. Recent resurgence of mumps in the United States. N Engl J Med. 2008;358(15):1580-9.

34. Rubin SA, Qi L, Audet SA, Sullivan B, Carbone KM, Bellini WJ, et al. Antibody induced by immunization with the Jeryl Lynn mumps vaccine strain effectively neutralizes a heterologous wild-type mumps virus associated with a large outbreak. J Infect Dis. 2008;198(4):508-15.

35. Whelan J, van Binnendijk R, Greenland K, Fanoy E, Khargi M, Yap K, et al. Ongoing mumps outbreak in a student population with high vaccination coverage, Netherlands, 2010. Euro Surveill. 2010;15(17):pii=19554. Available from: http://www. eurosurveillance.org/ViewArticle.aspx?Articleld=19554 